\title{
The ABCs of Buying and Maintaining a Surgical Instrument
}

\section{Sangamesh B. Tondare ${ }^{1}$}

Received: 17 January 2020 / Accepted: 24 April 2020 / Published online: 8 May 2020

(C) Association of Surgeons of India 2020

Surgeons have been operating since time immemorial. Whenever surgeons and hospital managements are out to buy surgical instruments, the common factor sought is consistency, durability, and economical. Although it is difficult to get all three parameters at a place, not much has been described when one goes out to buy surgical instruments. For a surgeon investment in surgical instruments is an asset.

For a new passed out surgeon after acquiring his degree and planning to start surgical private practice, unconscious mind overrules conscious mind, and it is the brand suggested by seniors and colleagues for buying instrument.

For the quality of surgical instruments, BS (British standard) and ISO (international organization of standardization) have been published which change from time to time.

In an Indian setup for the rural surgeons and young surgeons, this is a simple procedure to follow while buying surgical instruments (Table 1) and over a period of time to maintain the surgical instruments (Table 2).

Although it is a basic guide, the tables can be modified, and additions can be made with the vast experiences of the senior surgeons in ASI (Association of Surgeons of India).
Table 1 New surgical instrument
A Alignment (check for the relative position regarding straightness, angle, and curvature if applicable)
B Breakability (enquire about hardness certification)
C Corrosiveness (tells regarding the guarantee of longevity)
D Dimensions (for comparison with a standard instrument)
E Economical (is the instrument worth for the surgeon or the hospital where he works?)
F Fineness (for instruments like scissors for fine cutting)
G Grip (does it hold the structures properly?)

Table 2 Old surgical instrument
A Alignment (check for the relative position when the instrument was brought)
B Burrs (repeated use causes burring of instruments)
C Cleanliness (check for residual tissue in grooves, fenestration, and ratchet)
D Damages (check for damage to protective coat, ratchet, and grip)
E Edges (check for retained sharpness on the edge of instrument)
$\mathrm{F}$ Functioning (is the instrument functioning the way when it was brought?)
G Grid (check for alignment of shank)

Sangamesh B. Tondare

amith.sangamesh@yahoo.com; amith2007ind@gmail.com

1 Department of General Surgery, Gulbarga Institute of Medical Sciences, Kalaburgi (Gulbarga), India
Acknowledgment I would like to thank my teachers, seniors, and colleagues.

\section{Compliance with Ethical Standards}

Conflict of Interest The author declares no conflict of interest.

Publisher's Note Springer Nature remains neutral with regard to jurisdictional claims in published maps and institutional affiliations. 